\title{
Barriers to the Use of Health Services among Deaf and Hard of Hearing Adults in Greece: a Cross-Sectional Study
}

DOI:

10.5750/ejpch.v6i4.1566

\section{Document Version}

Accepted author manuscript

Link to publication record in Manchester Research Explorer

\section{Citation for published version (APA):}

Tsimpida, D., Kaitelidou, D., \& Galanis, P. (2018). Barriers to the Use of Health Services among Deaf and Hard of Hearing Adults in Greece: a Cross-Sectional Study. European journal for Person Centred Healthcare , 6(4), 638. https://doi.org/10.5750/ejpch.v6i4.1566

\section{Published in:}

European journal for Person Centred Healthcare

\section{Citing this paper}

Please note that where the full-text provided on Manchester Research Explorer is the Author Accepted Manuscript or Proof version this may differ from the final Published version. If citing, it is advised that you check and use the publisher's definitive version.

\section{General rights}

Copyright and moral rights for the publications made accessible in the Research Explorer are retained by the authors and/or other copyright owners and it is a condition of accessing publications that users recognise and abide by the legal requirements associated with these rights.

\section{Takedown policy}

If you believe that this document breaches copyright please refer to the University of Manchester's Takedown Procedures [http://man.ac.uk/04Y6Bo] or contact uml.scholarlycommunications@manchester.ac.uk providing relevant details, so we can investigate your claim.

\section{OPEN ACCESS}




\title{
Barriers to the use of health services among deaf and hard of hearing adults in Greece: a Cross-Sectional Study
}

\author{
Dialechti Tsimpida $\mathrm{MSc}^{\mathrm{a}}$, Daphne Kaitelidou $\mathrm{PhD}^{\mathrm{b}}$ and Petros Galanis MPH $\mathrm{PhD}^{\mathrm{c}}$ \\ a Psychologist, Faculty of Economics and Management, Open University of Cyprus, Nicosia, Cyprus \& PhD Candidate, \\ Manchester Centre for Audiology and Deafness (ManCAD), Division of Human Communication, Development and \\ Hearing, School of Health Sciences, Faculty of Biology, Medicine and Health, University of Manchester, Manchester \\ Academic Health Science Centre, Manchester, UK \\ b Associate Professor, Center for Health Services Management and Evaluation, Department of Nursing, National \& \\ Kapodistrian University of Athens, Athens, Greece \\ c Senior Researcher, Center for Health Services Management and Evaluation, Department of Nursing, National \& \\ Kapodistrian University of Athens, Athens, Greece
}

\begin{abstract}
Rationale, Aims and Objectives: To explore the issues related to the use of health services by deaf and hard of hearing adults in Greece.

Method: The study population consisted of 140 adults with hearing loss (86 deaf and 54 hard of hearing). We gathered information about sociodemographic characteristics, use of health services characteristics, satisfaction from health providers and complaints during the use of health services.

Results: A considerable percentage of the participants did not make appropriate use of healthcare services, as they made avoidable visits to emergency departments even for minor, short-term conditions $(p=0.002)$ or used to just wait for the symptoms to pass in an illness occurrence $(\mathrm{p}=0.06)$. They also experienced major difficulties as part of the health visit $(\mathrm{p}=0.01)$ and the quality of communication with health providers $(\mathrm{p}=0.002)$. The absence of assistive technology, along with the lack of low availability of Sign Language interpreters, were important barriers for those that communicate in Sign Language. Regarding the engagement with healthcare providers, there were high rates of dissatisfaction from doctors, nurses and receptionists related to issues during the use of health services.

Conclusions: Our results underscore the fact that deaf and hard of hearing persons constitute a minority population that experience major barriers during the use of health services and considerable difficulties in the healthcare provider-patient relationship. In light of these findings, a special effort must be made to ensure that deaf and hard of hearing individuals receive appropriate, ethical and person-centered healthcare.
\end{abstract}

\section{Keywords}

Deaf, doctor-patient communication, hard of hearing, hearing health inequalities, person-centered healthcare, use of health services

\section{Correspondence address}

Ms. Dialechti Tsimpida, Manchester Centre for Audiology and Deafness (ManCAD), Division of Human Communication, Development and Hearing, School of Health Sciences, Faculty of Biology, Medicine and Health, University of Manchester, Manchester Academic Health Science Centre, A4.01 Ellen Wilkinson Building, Oxford Road, Manchester, M13 9PL, UK. E-mail address: dialechti.tsimpida@postgrad.manchester.ac.uk

Accepted for publication: 4 May 2018

\section{Introduction}

Although the consequences of hearing loss are rarely obvious, hearing loss is a major global health challenge, given that over $5 \%$ of the world's population and therefore some 360 million people have disabling hearing loss (hearing threshold of 41 decibels or greater in the better ear) [1]. By 2030, hearing loss is projected to be in most countries among the top ten causes of burden of disease, with the associated detrimental social and economic effects
[2]. International studies have shown that deaf and hard of hearing people face many barriers to receiving adequate healthcare, have a deficiency in knowledge of health matters and use health services in a different way compared to hearing people. They are unsatisfied with their communication with health providers and are less satisfied with the health services they receive [3-5]. Also, it is more likely for these people to avoid visits to health services, due to the difficulties in their communication 
with healthcare providers and the lack of available interpreters $[4,6]$.

In Greece, people with hearing disability are systematically absent from health policy and planning, despite the fact that hearing loss is an important public health and Societal concern [7]. Since 2010, Greece's economy has been severely affected by the economic crisis, characterized by the loss of more than $25 \%$ of GDP, international bailouts and the adoption of large-scale austerity measures, which have involved substantial reductions in public spending. As a consequence, the government grant for the payment of sign language interpreters has significantly reduced. However, the contribution of interpreting to the quality of life of Deaf/HH sign language users is enormous, since only via the presence of an interpreter can these people enjoy interactive and effective communication in all aspects of their life, covering all their communications needs, including the use of and access to healthcare services. Since 2011, Sign Language users in Greece have the right to only 25 hours free interpretation per year to meet all their communication needs, while prior to this time the costs of interpretation were fully paid by the State and the available interpretation hours per person were unlimited. When sign language users consume the 25 free hours of interpretation, they then have to pay interpretation costs privately, which are much higher when related to health issues. This means that many people who communicate primarily in sign language face significant barriers during the utilization of health services and especially during their communication with health professionals [5]. Until recently, no formal policy regarding the use of healthcare services existed, mainly due to a lack of sound data for the epidemiological profile of deaf and hard of hearing people and the use of health services by them. This present study aimed to address this observation by investigating the perceived barriers to the utilization of healthcare services by deaf and hard of hearing people in Greece.

\section{Methods and Materials}

\section{Participants}

A cross-sectional study was conducted and the study population consisted of 140 young and middle-aged adults (18-65 years) with hearing loss (86 d/Deaf and 54 hard of hearing). There are several groups included within the broad "deaf and hard of hearing" category and factors that must be considered with Deaf/HH sub-populations include (a) degree of hearing loss, (b) age of onset of loss (prelingual/post-lingual), (c) preferred language and (d) psychological issues [8]. Following a convention proposed by James Woodward [9], we use the lowercase deaf when referring to the audiological condition of not hearing and the uppercase Deaf when referring to a particular group of deaf people who share a language and a culture. The distinction between the terms "deaf" and "hard of hearing" is often made using different criteria as it has strong ties with the individuals' ideological positions about education, social inclusion and/or rehabilitation of people with hearing loss [8].

In this study, the participants with hearing loss were categorized using a combination of cultural selfidentification and the preferred method of communication, a classification that fits best with the population with hearing loss in Greek culture and is intentionally differentiated from their solely hearing loss severity:

Deaf - Persons referred to as Deaf (upper case D) typically belong to the Deaf Community and use Greek Sign Language as a primary language [9].

Deaf - Persons referred to as deaf (lower case d), that do not consider themselves members of the Deaf Community and use non-signing communication [10].

Hard of hearing that communicate in terms of auditory-verbal approach [11].

Hard of hearing who communicate via lip-reading [12].

Hard of hearing who communicate using Greek Sign Language as a preferred method of communication [9].

Regarding the sampling method, there is no accurate census of deaf and hard of hearing in Greece since, excluding the members of the first subcategory who are registered in deaf clubs, members of the subcategories of this population are extremely difficult to locate. Thus, probability or random sampling could not be realized and therefore a convenience sampling technique was employed. With regard to the deaf and hard of hearing participants that communicate via sign language, the recruitment was conducted by visiting the 5 Deaf Clubsmembers of the Hellenic Federation of the Deaf which are located in Attica (4 in Athens and one in Korydallos).

\section{Materials}

Data collection concerning the use of health services of the deaf and hard of hearing was enabled by using a questionnaire that was specially developed for this study, based on the relevant literature. The questionnaire consisted of 3 sections. The first section explained the purpose of the questionnaire and provided a contact name and address for any enquiries regarding the study. The second section consisted of questions on sociodemographic data such as gender, age, marital status, number of household members, complete educational status, work status and income. The third section consisted of questions on participants' (a) utilization of health services characteristics, (b) complaints during the use of health services and (c) satisfaction from health providers. Internal consistency for the 12 questions about satisfaction from health providers during the use of health services was calculated by Cronbach's alpha and was found equal to 
0.92, indicating excellent internal consistency of the questionnaire.

A pilot study with 6 Deaf adults was carried out, in order to check the comprehensibility of the questionnaire, as the written form of spoken language is a second language for them (Greek Law 3699/2008). The 6 participants in the pilot study were representative of the overall Deaf signers that were enrolled into our study, as they represent them unanimously on a regular basis in the Community and they understand their educational and other needs. The face validity of the questionnaire was very good and no significant corrections were made.

\section{Procedure}

The data collection was conducted in person and the questions to be signed in GSL, when necessary, in order to improve accessibility and minimize the language barrier for Deaf, as they completed a lengthy written questionnaire not in their primary language. The completion of the questionnaire by the deaf and hard of hearing non-users of sign language and by the hearing participants was conducted in person, following a convenience sampling technique.

All participants were informed about the aim and procedures of this study (additionally in Greek Sign Language) and gave their consent. The personal data of the participants were not registered at any stage of the study. Participation in this study was voluntary and anonymous. The previous engagement of the first author in the Deaf community, as she is certified in GSL, reinforced the feelings of trust and comfortability of the participants leading to an excellent response rate (91\%).

All procedures performed in this study involving human participants were in accordance with the ethical standards of the institutional and/or national research committee and with the 1964 Helsinki Declaration and its later amendments or comparable ethical standards. The study protocol and the questionnaire were approved by the Hellenic Federation of the Deaf, which is the official representative association of deaf and hard of hearing people in Greece, with the reference number 435/13-32015. Questionnaires were distributed and collected from April 2015 to June 2015.

\section{Statistical analysis}

Continuous variables are presented as mean (standard deviation, SD), while categorical variables are presented as absolute and relative frequencies. The normality assumption was evaluated using Kolmogorov-Smirnov criterion ( $p>0.05$ for all variables), histograms and normal probability plots.

Associations between categorical variables were assessed with a chi-square test and between categorical and ordinal variables with a chi-square trend test. Student's ttest was applied for the association between a quantitative variable and a dichotomous one when the quantitative variable followed normal distribution. In addition, we used Analysis of Variance (ANOVA) to assess the relationship between a quantitative variable and a categorical variable when the quantitative variable followed normal distribution and Kruskal-Wallis test when the quantitative one did not follow normal distribution. Due to the small number of the participants we did not perform multivariate analyses. Work status was not used as independent variable because of the small number of participants in several categories $(\mathrm{n} \leq 10)$.

The 5 designed subcategories of population with hearing loss were not finally used as independent variables because of the exceptionally small number of participants in several categories $(\mathrm{n} \leq 10)$. As a result, the classification was limited to the 3 bigger categories (deaf/hard of hearing) and it was not possible to take into consideration the exact language preferences of the participants, but only their cultural self-identification. That means that the "deaf category" in the statistical analysis finally included those that self-identified themselves as severely or profoundly deaf (category No1 and No2), while the "hard of hearing category" included those that self-identified themselves as having mild, moderate or moderately severe hearing loss (category No3 and No4). The two-tailed significance level was set as $\leq 0.05$. Data were analyzed using IBM SPSS 21.0 (IBM Corp. Released 2012. IBM SPSS Statistics for Windows, Version 21.0. Armonk, NY: IBM Corp).

\section{Results}

Sociodemographic characteristics are presented in Table 1. For the $91.9 \%$ of the deaf the Greek Sign Language was the preferred method of communication, while for the 8.1\% was not. Among the 54 hard of hearing, the $20.4 \%$ preferred to communicate via the oral method, the $50 \%$ via the lip-reading technique and the $29.6 \%$ via the Greek Sign language.

Participants' use of health services characteristics are presented in Tables 2, 3 and 4. Regarding the use of health services in the past 12 months, the deaf were more often ill than the hard of hearing $(\mathrm{p}=0.02)$ and they visited a public hospital to cope with their illness $(p=0.002)$. In this study we found that the deaf participants did not make appropriate use of healthcare services, as the $60.5 \%$ of them made visits to emergency departments even for minor, short-term conditions ( $\mathrm{p}=0.002)$.

In addition, deaf participants seem to be confronted with barriers when using health services; the $73.3 \%$ had complaints for the lack of assistive technology (e.g., videointerpretation, communication support technology, screens with health messages in sign language etc.), $(\mathrm{p}<0.001)$. Also, the $70.9 \%$ complained for the absence of ambulance personnel that can communicate in sign language and the $79.1 \%$ for the absence of hospital staff that can communicate in sign language ( $<<0.001$ in both).

The small number, the lack of availability and the absence of sign language interpreters as full time staff in the hospitals, were factors for complaining for the deaf participants, in percentages $57 \%, 75.6 \%$ and $80.2 \%$, respectively $(p<0.001)$. This is very crucial, as the existence of a communication assistant with a doctor or during a health visit was characterized as "very important" for the $79.1 \%$ of the deaf participants $(p<0.001)$ and they 
Table 1 Sociodemographic data of the participants

\begin{tabular}{|c|c|c|}
\hline Variable & Hard of Hearing & Deaf \\
\hline \multicolumn{3}{|l|}{ Gender } \\
\hline Women & $32(59.3)$ & $46(53.5)$ \\
\hline Men & $22(40.7)$ & $40(46.5)$ \\
\hline Age (years) ${ }^{a}$ & $41.4(11.8)$ & $38.1(10.7)$ \\
\hline \multicolumn{3}{|l|}{ Marital Status } \\
\hline Unmarried & $16(29.6)$ & 37 (43) \\
\hline In cohabitation & $14(25.9)$ & $11(12.8)$ \\
\hline Married & $14(25.9)$ & $20(23.3)$ \\
\hline Divorced & $7(13)$ & $13(15.1)$ \\
\hline Widowed & $3(5.6)$ & $5(5.8)$ \\
\hline Number of household members ${ }^{b}$ & $2.7(1.2)$ & $2.6(1.2)$ \\
\hline Existence of hearing person in household & $38(70.4)$ & 37 (43) \\
\hline \multicolumn{3}{|l|}{ Educational attainment } \\
\hline Junior High & $4(7.4)$ & $11(12.8)$ \\
\hline High School & $19(35.2)$ & $59(68.6)$ \\
\hline College & $3(5.6)$ & $2(2.3)$ \\
\hline Technological Educational Institution & $5(9.3)$ & $0(0)$ \\
\hline University & $11(20.4)$ & $10(11.6)$ \\
\hline Master's/Doctorate degree & $12(22.2)$ & $4(4.7)$ \\
\hline \multicolumn{3}{|l|}{ Work Status } \\
\hline Unemployed & $8(14.8)$ & $21(24.4)$ \\
\hline Household keeper & $3(5.6)$ & $5(5.8)$ \\
\hline Income collection & $0(0)$ & $1(1.2)$ \\
\hline Student & $1(1.9)$ & $5(5.8)$ \\
\hline Unskilled worker & $4(7.4)$ & $6(7.0)$ \\
\hline Private sector employee & 10 (18.5) & 30 (34.9) \\
\hline Public sector employee & $18(33.3)$ & $16(18.6)$ \\
\hline Entrepreneur & $6(11.1)$ & $0(0)$ \\
\hline Retired & $4(7.4)$ & $2(2.3)$ \\
\hline Family annual income (euro) ${ }^{\mathrm{b}}$ & $15,000(75,000)$ & $15,000(49,000)$ \\
\hline
\end{tabular}

Values are expressed as $\mathrm{n}(\%)$ unless otherwise is indicated.

${ }^{\mathrm{a}}$ Mean (standard deviation), ${ }^{\mathrm{b}}$ Median (range)

Table 2 Participants' utilization of health services characteristics

\begin{tabular}{|c|c|c|c|}
\hline Variable & Hard of Hearing & Deaf & P-value \\
\hline Illness occurrence during the past 12 months & & & $0.02^{\mathrm{a}}$ \\
\hline Yes & $35(64.8)$ & 73 (84.9) & \\
\hline No & $19(35.2)$ & $13(15.1)$ & \\
\hline $\begin{array}{l}\text { Number of illness occurrence during the past } 12 \\
\text { months }^{\mathrm{b}}\end{array}$ & $3.9(1.9)$ & $3.8(1.9)$ & $0.8^{\mathrm{c}}$ \\
\hline \multicolumn{4}{|l|}{ Management of illness occurrence } \\
\hline Visit to a private doctor & & & $0.07^{\mathrm{a}}$ \\
\hline No & $31(57.4)$ & 36 (41.9) & \\
\hline Yes & $23(42.6)$ & 50 (58.1) & \\
\hline
\end{tabular}


Visit to emergency department

0.002

No

36 (66.7)

34 (39.5)

Yes

18 (33.3)

$52(60.5)$

Visit to outpatient clinic

No

50 (92.6)

$4(7.4)$

$74(86)$

Yes

$12(14)$

Visit to community health center

No

54 (100)

$0(0)$

Yes

Visit to hospital department/private clinic

No

Yes

Health and medication advice from pharmacist

No

Yes

Health and medication advice from friend(s)

No

Yes

Health and medication advice from a family member

No

Yes

Just wait for the symptoms to pass

No

Yes

Visit to a private doctor/private clinic during the past 12 months

No
Yes
Number of visits to private doctor/private clinic during
the past 12 months ${ }^{\text {b }}$
Reason for visiting a private doctor/clinic

Long waiting time to book an appointment in public health services
No
Yes

Better quality of healthcare provision in private

practice

No

Better behavior toward patients in private practice

No

Lack of sign language interpreter availability the day of appointment in the public health service

\begin{tabular}{lcc} 
No & $49(90.7)$ & $57(66.3)$ \\
Yes & $5(9.3)$ & $29(33.7)$ \\
\hline
\end{tabular}

$43(79.6) \quad 73(84.9)$

$11(20.4)$

$0.3^{\mathrm{a}}$

$45(83.3) \quad 66(76.7)$

$9(16.7) \quad 20(23.3)$

48 (88.9) $\quad 73(84.9)$

$6(11.1)$

$47(87) \quad 78(90.7)$

$7(130) \quad 8(9.3)$

$0.06^{\mathrm{a}}$

43 (79.6) $\quad 54(60.7)$

$11(20.4)$

$0.7^{\mathrm{a}}$

12 (34.3) $23(31.5)$

$23(65.7) \quad 50(68.5)$

$2.6(1.6)$

$0.02^{\mathrm{c}}$

$0.003^{\mathrm{a}}$

$\begin{array}{ll}41(75.9) & 44(51.2) \\ 13(24.1) & 42(48.8)\end{array}$

$13(24.1) \quad 42(48.8)$

$\begin{array}{ll}38(70.4) & 52(60.5) \\ 16(29.6) & 34(39.5)\end{array}$

$38(70.4) \quad 52(60.5)$

16 (29.6) $\quad 34(39.5)$

$0.001^{\mathrm{a}}$

Values are expressed as n (\%) unless otherwise is indicated.

${ }^{*} p<0.05,{ }^{\mathrm{a}} \mathrm{x}^{2}$ test,${ }^{\mathrm{b}}$ Mean (standard deviation), ${ }^{\mathrm{c}} \mathrm{t}$ - test 
Table 3 Participants' complaints during the use of health services

\begin{tabular}{|c|c|c|c|}
\hline Variable & Hard of Hearing & Deaf & P-value \\
\hline \multicolumn{4}{|l|}{ Complaints referring to health visit } \\
\hline Poor quality of communication & & & $0.2^{\mathrm{a}}$ \\
\hline No & $17(31.5)$ & $19(22.1)$ & \\
\hline Yes & $37(68.5)$ & $67(77.9)$ & \\
\hline Difficulty in understanding the medical instructions & & & $0.002^{\mathrm{a}}$ \\
\hline No & $32(59.3)$ & $71(82.6)$ & \\
\hline Yes & $22(40.7)$ & 15 (17.4) & \\
\hline Low duration of health visit & & & $0.1^{\mathrm{a}}$ \\
\hline No & $19(35.2)$ & $20(23.3)$ & \\
\hline Yes & 35 (64.8) & $66(76.7)$ & \\
\hline High cost of health visit & & & $0.01^{\mathrm{a}}$ \\
\hline No & $27(50)$ & $25(29.1)$ & \\
\hline Yes & $27(50)$ & $61(70.9)$ & \\
\hline \multicolumn{4}{|l|}{ Complaints referring to the procedure } \\
\hline Excessively bureaucratic procedures & & & $0.1^{\mathrm{a}}$ \\
\hline No & $9(16.7)$ & $26(30.2)$ & \\
\hline Yes & $45(83.3)$ & $60(69.8)$ & \\
\hline $\begin{array}{l}\text { Lack of equipment for Deaf and hard of hearing that } \\
\text { communicate via Sign Language (p.e. screens with } \\
\text { health messages in Sign Language, video- } \\
\text { interpretation } \text { etc.) }\end{array}$ & & & $<\mathbf{0 . 0 0 1}^{\mathrm{a}}$ \\
\hline No & $36(66.7)$ & $23(26.7)$ & \\
\hline Yes & $18(33.3)$ & $63(73.3)$ & \\
\hline $\begin{array}{l}\text { Lack of } 24 \mathrm{~h} \text { Emergency Contact Phone for } \\
\text { communication via text messages }\end{array}$ & & & $<\mathbf{0 . 0 0 1}^{\mathrm{a}}$ \\
\hline No & $24(44.4)$ & $16(18.6)$ & \\
\hline Yes & $30(55.6)$ & $70(81.4)$ & \\
\hline $\begin{array}{l}\text { Absence of ambulance personnel that can } \\
\text { communicate in Sign Language }\end{array}$ & & & $<\mathbf{0 . 0 0 1}^{\mathrm{a}}$ \\
\hline No & $38(70.4)$ & $25(29.1)$ & \\
\hline Yes & $16(29.6)$ & $61(70.9)$ & \\
\hline $\begin{array}{l}\text { Absence of hospital staff that can communicate in } \\
\text { Sign Language }\end{array}$ & & & $<\mathbf{0 . 0 0 1}^{\mathrm{a}}$ \\
\hline No & $42(77.8)$ & $18(20.9)$ & \\
\hline Yes & $12(22.2)$ & $68(79.1)$ & \\
\hline Complaints referring to Sign Language interpreters & & & $<\mathbf{0 . 0 0 1}^{\mathrm{a}}$ \\
\hline \multicolumn{4}{|l|}{ Small number } \\
\hline No & $44(81.5)$ & $37(43)$ & \\
\hline Yes & $10(18.5)$ & $49(57)$ & \\
\hline Lack of availability & & & $<\mathbf{0 . 0 0 1}^{\mathrm{a}}$ \\
\hline No & $44(81.5)$ & $21(24.4)$ & \\
\hline Yes & $10(18.5)$ & $65(75.6)$ & \\
\hline $\begin{array}{l}\text { Absence of Sign Language interpreters in hospitals } \\
\text { (full-time staff) }\end{array}$ & & & $<\mathbf{0 . 0 0 1}^{\mathrm{a}}$ \\
\hline No & $40(74.1)$ & $17(19.8)$ & \\
\hline Yes & $14(25.9)$ & $69(80.2)$ & \\
\hline $\begin{array}{l}\text { Importance of existence of a communication assistant } \\
\text { with a doctor or during a health visit }\end{array}$ & & & $<\mathbf{0 . 0 0 1}^{\mathrm{b}}$ \\
\hline Unimportant & $7(13)$ & $2(2.3)$ & \\
\hline Of little importance & $9(16.7)$ & $6(7)$ & \\
\hline Moderately important & $12(22.2)$ & $4(4.7)$ & \\
\hline
\end{tabular}




\begin{tabular}{lcc} 
Important & $15(27.8)$ & $6(7)$ \\
Very important & $11(20.4)$ & $68(79.1)$ \\
Preference for a communication assistant in a health & & \\
visit & & \\
$\quad$ Sign Language interpreter & $10(18.5)$ & $66(76.7)$ \\
Hearing family member & $20(37)$ & $6(7)$ \\
Hearing friend & $9(16.7)$ & $3(3.5)$ \\
Preference for non-provision of assistance & $15(27.8)$ & $11(12.8)$ \\
\hline $\begin{array}{l}\text { Values are expressed as } \mathrm{n}(\%) \text { unless otherwise is indicated. } \\
* p<0.05,{ }^{\mathrm{a}} \mathrm{x}^{2} \text { test, }{ }^{\mathrm{b}} \mathrm{x}^{2} \text { test for trend }\end{array}$
\end{tabular}

preferred a sign language interpreter as a communication assistant in a health visit, in a percentage of $76.7 \%$, $(p<0.001)$. The lack of a 24 hour Emergency Contact number for communication via text messages was a complaint for both deaf and hard of hearing participants, in percentages $81.4 \%$ and $55.6 \%$, respectively $(p<0.001)$. Furthermore, the deaf and hard of hearing had many complaints referring to the health visit; the poor quality of communication was a complaint for the $77.9 \%$ of deaf and the $68.5 \%$ of hard of hearing $(p=0.2)$. Also, the low duration of the medical visit was a complaint for the $76.7 \%$ of deaf and the $64.8 \%$ of hard of hearing participants $(\mathrm{p}=0.1)$.

Regarding the engagement with healthcare providers, the $46.6 \%$ of deaf and the $63 \%$ of hard of hearing participants were "very dissatisfied" or "dissatisfied" with the doctors in relation to the provision of health information about their medical condition $(p=0.2)$. In addition, satisfaction referring to friendly behaviour and politeness of healthcare providers was low. The $40.7 \%$ of deaf and the $44.5 \%$ of hard of hearing were "very dissatisfied" or "dissatisfied" with the doctors $(p=0.4)$, while the rates of satisfaction with the nurses and receptionist were $24.4 \%, 24.1 \%$ and $81.4 \%$, $75.9 \%$ for deaf and hard of hearing participants, respectively $(\mathrm{p}=0.3$ and $\mathrm{p}=0.2$ ). These findings are of relevance tothe fact that the $39.5 \%$ of deaf and the $29.6 \%$ of hard of hearing preferred to visit a private doctor/clinic during the past 12 months, instead of booking an appointment in public health services, seeking better quality of healthcare provision and better behaviour of doctors toward patients $(p=0.2)$ (Table 2). This fact is noteworthy, although the high level of fees charged for a visit in the private health sector were a valid complaint for the majority of participants $(p=0.01)$.

Lastly, the satisfaction with receptionists during the use of health services was also low; the $81.4 \%$ of deaf and $76 \%$ of hard of hearing were "very dissatisfied" or "dissatisfied" with reference to the fast patient service $(p=0.4)$ (Table 4). As regards to the genuine interest and respect for them as patients, the percentages were $87.2 \%$ and $74.1 \%$, respectively $(\mathrm{p}=0.06)$.

\section{Discussion}

Previous studies have revealed that only the existence of a sign language interpreter can guarantee the effective healthcare provider-patient communication for those that communicate primarily in sign language [13,14]. The complaints that the participants had in this study referring to the sign language interpreters were referred to also in the study of Steinberg et al. [5]. In that study, positive experiences were reported by the deaf participants as a function of the presence of medically experienced certified interpreters, healthcare practitioners with sign language skills and practitioners who made an effort to improve healthcare provider-patient communication. Previous studies have shown that the presence of sign language interpreters as full-time staff in the hospitals could serve as a solution to this problem $[13,15]$. In this study, this was an additional reason for the deaf to make complaints about the health services, as sign language interpreters are totally absent in Greek hospitals. In addition, the lack of equipment for the deaf and hard of hearing that communicate via Sign Language (e.g., screens with health messages in Sign Language, video-interpretation etc.) erects another barrier for those that communicate in sign language and this also was found in the study of Sheppard [16] where the deaf adults experienced significant healthcare disparities. In general, the population with hearing loss faces difficulties in healthcare settings when information is not provided visually, when a sign language interpreter is not provided and where the use of devices, or special equipment and aids, are not adapted to their needs (e.g., visual warning or vibration etc.) [17].

As for doctor-patient communication, the doctors may believe that they communicate effectively with their patients, but the patients do not always share the same opinion [18,19]. In this study the hard of hearing participants had more difficulty in understanding medical advice compared to the deaf participants $(p=0.002)$. This is not surprising, because in this study the $50 \%$ of the hard of hearing participants used to communicate via lip-reading and previous studies have shown that in that case there is frequently miscommunication with the health provider [2022]. Previous studies [19,23] have also observed that persons who are deaf or hard of hearing and communicate via lip-reading or written notes, face considerable barriers to communicating with physicians. Complaints relating to the poor quality of communication and the low duration of the health visit were not unexpected, as those with hearing loss need more time during an appointment to establish an effective communication with hearing people and to understand medical advice [24].

The major difficulties that the deaf and hard of hearing experienced during communication with health providers had an impact also on their satisfaction during the use of 


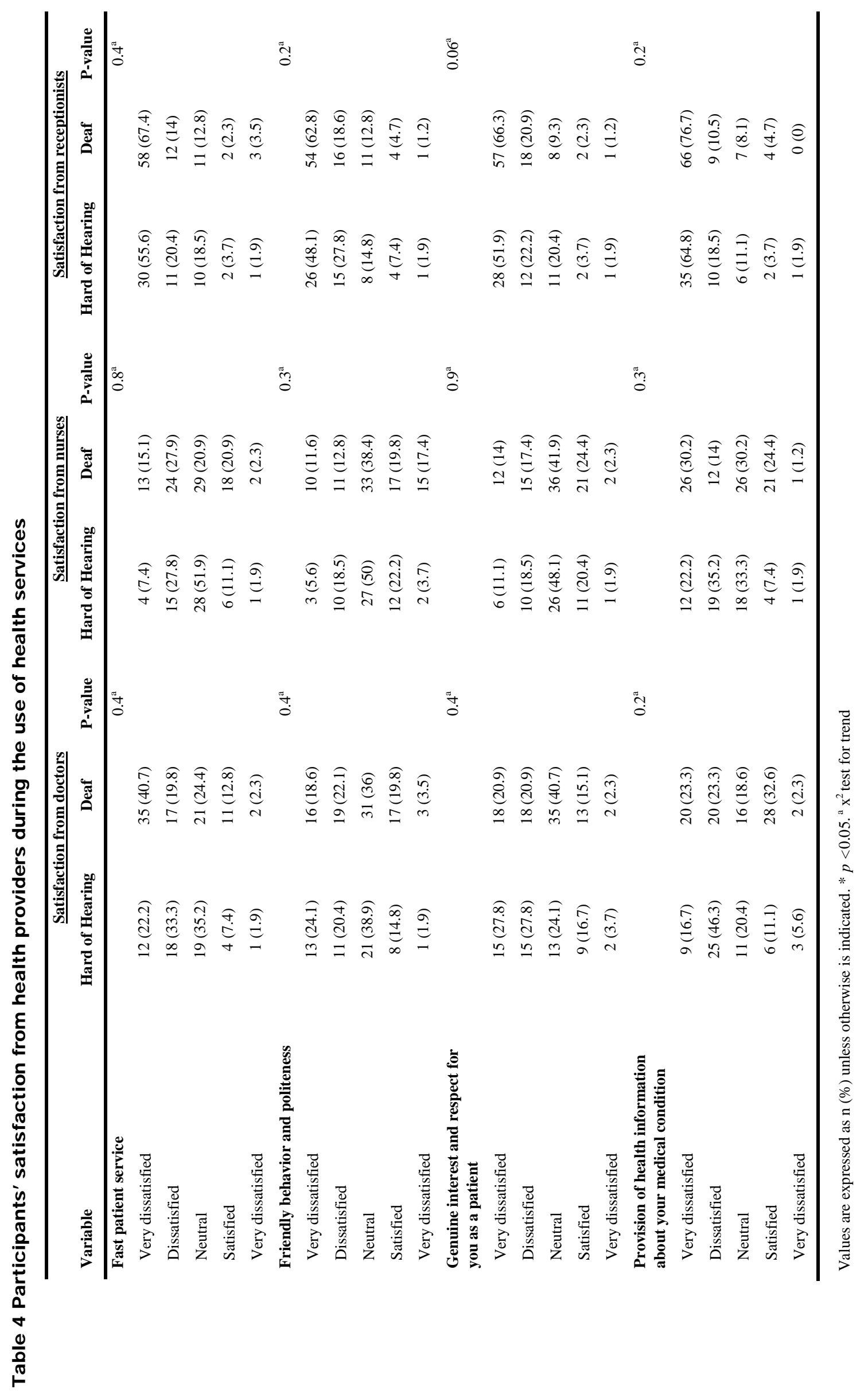


health services, for example, in terms of the provision of health information about their medical condition. A study in the United Kingdom [25], revealed that the 77\% of Sign Language users faced difficulties in communication with physicians in hospitals. Of them, 33\% left the consultation having many questions and feelings of uncertainty about their health condition. The Action On Hearing Loss study [26], referring to patient experiences during consultations and whether they had ever been unclear after a GP consultation, revealed that more than one-quarter (28\%, $\mathrm{n}=170$ ) of respondents had been unclear about a diagnosis. In addition, around one-quarter $(26 \%, n=158)$ had been unclear about the health advice they were provided with and approximately two-fifths $(19 \%, n=115)$ had been unclear about their medication. According to McKee et al. [27], the quality of communication between patients and providers is an important determinant of whether patients seek, understand and adhere to providers' preventive services recommendations, which has been associated with improved healthcare utilization and outcomes. Ensuring effective communication is essential to safe, timely, efficient and patient-centered care [23]. Failure to communicate in appropriate formats leads to problems with compliance and attendance, wastes time and human resources and potentially also causes delays in diagnoses and treatment for these individuals [28-31]. The particular challenges they face with regard to their communication with healthcare professionals are probably the "key", behind their different use of health services, as they face many gaps in knowledge on how to 'behave' within the health system [4,5,32-34]. The high rates of seeking health and medication advice from friends and family members, or just the waiting for the symptoms to pass in an illness occurrence (Table 2), reflect the reality of their difficulties. In addition, the major difficulties that the deaf and hard of hearing experienced during communication with health providers may be the reason behind the inappropriate use of healthcare services; for example, avoidable visits to emergency departments even for minor, short-term conditions, instead of adopting a primary healthcare process. This frequent use of emergency departments' units also reflects their attempt to resolve the uncertainty they feel about health issues [3,16,34-37].

Another important issue was the high rates of dissatisfaction among the participants in relation to the behavior and politeness of the medical providers. Health professionals should be aware of the incorrect assumptions about disability that result from stigmatized views about people with disabilities. Some studies have found that medical students have more negative attitudes to disability than the general norm, as many courses of instruction medicalize disability, fail to take a holistic view of health and ignore the human rights of people with disabilities, which influences the quality of doctor-patient communication [23,29]. All participants in the Sheppard study [16] described hospitals and provider offices as 'scary' and 'intimidating' and doctors, nurses and receptionists as 'frequently impatient'. Other studies have also revealed that the deaf and hard of hearing participants felt that some providers did not respect the intelligence, motivation and desire to be more involved in the process of understanding the medical interventions and the decisionmaking on issues related to their health [5,23,25,38-40].

Lastly, it is worth mentioning the importance of receptionists. Health policy typically ignores receptionists, although the experience of a health service can sometimes be decided by how good the receptionist is. In our study, despite the existence of legislation in Greece for priority on health services access for hearing impaired people, receptionists appeared to be unaware of this. The low levels of satisfaction relating as to whether receptionists show "genuine interest and respect for them as a patient" were shown also in other studies. In the SignHealth study [41], 39.8\% $(n=119)$ of the participants answered that the receptionists were "not very helpful" or "not helpful at all”. In addition, in the study of Iezzoni et al. [23], the deaf and hard of hearing participants had difficulties interacting with office staff, including in waiting rooms. Many people lost appointments that had been closed months before, even though they had attended the appointment because the information was not presented in an easily understandable manner. Overall, our study confirmed the findings of previous studies, where complex individual, interpersonal and systemic factors frequently lead deaf and hard of hearing individuals to receive inadequate, inappropriate and unethical healthcare.

There are several limitations when conducting a study among deaf and hard of hearing participants. However, the previous engagement of the first author in the deaf community, given her national certification in GSL, allowed many of these methodological issues to be overcome. The principal limitation of our study is that while the deaf population consists of subgroups with different cultural and communicational characteristics, it was not possible to take into consideration the language preferences of the participants, but only their cultural selfidentification. This should be considered by future studies aiming to assess health-related quality of life in a larger sample of population with hearing loss.

Observations were collected only in the Attica region, but there are large variations in the number of deaf and hard of hearing people in other regions. The conduct of studies with a collection of observations from the whole country could offer the possibility of an optimal investigation of the determinants associated with the outcome. In addition, due to the small number of the participants, we did not perform multivariate analyses and confounding is possible.

\section{Conclusions}

This study offers an insight into an important area of hearing loss research, a subject of extensive discussions globally [7]. The access to and use of health services without barriers is a clearly defined right of people with disabilities, as stated by the UN Convention on the Rights of People with Disabilities. Nevertheless, our results underscore the fact that deaf and hard of hearing persons constitute a minority population that experiences major barriers during the use of health services and considerable difficulties in the healthcare doctor-patient relationship. 
Future research should explore the perspective of clinicians when working with people with hearing loss and ways to improve communication, such as providing powerful and visually accessible communication using sign language and the implementation of important communication technologies. In addition, cultural awareness trainings for health professionals and programs that raise health knowledge in deaf communities could help in tackling these health inequalities.

\section{Conflicts of Interest}

The authors declare no conflicts of interest.

\section{References}

[1] World Health Organization. (2015). Fact sheet. Deafness and hearing loss. Available at: http://www.who.int/mediacentre/factsheets/fs300/en.

Accessed April 9, 2018.

[2] Mathers, C.D., Fat, D.M. \& Boerma, J. (2008). The global burden of disease: 2004 update. Geneva, Switzerland: World Health Organization. Available at: http://www.who.int/healthinfo/global_burden_disease/GB D_report_2004update_full.pdf. Accessed April 9, 2018.

[3] Barnett, S., McKee, M., Smith, S.R. \& Pearson, T.A. (2011). Deaf Sign Language Users, Health Inequities, and Public Health: Opportunity for Social Justice. Preventing Chronic Disease 8 (2) A45.

[4] Orsi, J., Margellos-Anast, H., Perlman, T., Giloth, B. \& Whitman, S. (2007). Cancer screening knowledge, attitudes, and behaviors among culturally Deaf adults: Implications for informed decision making. Cancer Detection and Prevention 31 (6) 474-479.

[5] Steinberg, A.G., Barnett, S., Meador, H.E., Wiggins, E.A. \& Zazove, P. (2006). Health care system accessibility. Experiences and perceptions of deaf people. Journal of General Internal Medicine 21 (3) 260-266.

[6] Kritzinger, J., Schneider, M., Swartz, L. \& Braathen, S.H. (2014). "I just answer 'yes' to everything they say": access to health care for deaf people in Worcester, South Africa and the politics of exclusion. Patient Education and Counseling 94 (3) 379-383.

[7] Hearing loss: an important global health concern. (2016). Lancet 387 (10036) 2351.

[8] Meador, H. \& Zazove, P. (2005). Health Care Interactions with Deaf Culture. Journal of the American Board of Family Medicine 18 (3) 218-222.

[9] Lampropoulou, V. (Ed.). (1999). Society and the Deaf: Community and Deaf culture. 1st Module of Training. Program EPEAEK, Patras: Department of Elementary Education. Patra: University of Patras Publications.

[10] Crystal, D. (3rd edn.). (2010). The Cambridge Encyclopedia of Language. Cambridge: Cambridge University Press.

[11] Cole, E.B. \& Flexer, C. (2015). Children with hearing loss: Developing listening and talking, birth to six. San Diego, CA: Plural Publishing.
[12] Woodhouse, L., Hickson, L. \& Dodd, B. (2010). Review of visual speech perception by hearing and hearing-impaired people: clinical implications. International Journal of Language \& Communication Disorders 44 (3) 253-270.

[13] Ubido, J., Huntington, J. \& Warburton, D. (2002). Inequalities in access to healthcare faced by women who are deaf. Health \& Social Care in the Community 10 (4) 247-253.

[14] Chilton, E. (1995). Ensuring effective communication: the duty of health care providers to supply sign language interpreters for deaf patients. Hastings Law Journal 47, 871.

[15] Cardoso, A.H., Rodrigues, K.G. \& Bachion, M.M. (2006). Perception of persons with severe or profound deafness about the communication process during health care. Revista latino-americana de enfermagem 14 (4) 553560.

[16] Sheppard, K. (2014). Deaf adults and health care: Giving voice to their stories. Journal of the American Association of Nurse Practitioners 26 (9) 504-510.

[17] Christophi, M. (2013). Accessibility and Disability. Athens: National Confederation of Disabled People (NCDP).

[18] Tannenbaum-Baruchi, C., Feder-Bubis, P., AdiniWeisel, B. \& Aharonson-Daniel, L. (2014). How deaf people cope in routine and emergency situations-suggested paths for thought and action. Harefuah 153 (9) 532-536, 558.

[19] Alexander, A., Ladd, P. \& Powell, S. (2012). Deafness might damage your health. Lancet 379 (9820) 979-981.

[20] Scheier, D.B. (2009). Barriers to health care for people with hearing loss: a review of the literature. Journal of the New York State Nurses Association 40 (1) 4.

[21] Pollard, R. \& Barnett, S. (2009). Health-related vocabulary knowledge among deaf adults. Rehabilitation Psychology 54 (2) 182-185.

[22] Phillips, B. (1996). Bringing culture to the forefront: Formulating diagnostic impressions of deaf and hard-ofhearing people at times of medical crisis. Professional Psychology: Research and Practice 27 (2) 137-144.

[23] Iezzoni, L., O’Day, B., Killeen, M. \& Harker, H. (2004). Communicating about Health Care: Observations from Persons Who Are Deaf or Hard of Hearing. Annals of Internal Medicine 140 (5) 356.

[24] Pagliuca, L.M., Fiuza, N.L. \& Rebouças, C.B. (2007). Aspects of nurses' communication with hearing impaired persons. Revista da Escola de Enfermagem da USP 41 (3) 411-418.

[25] Royal National Institute for the Deaf (RNID). (2004). A simple cure: a national report into deaf and hard of hearing people's experiences of the National Health Service. London: Royal National Institute for the Deaf. [26] Action on Hearing Loss. (2012). A report into the experiences of people with hearing loss when accessing healthcare. Available at:http://www.actiononhearingloss.org.uk/accessallareas.as px. Accessed April 9, 2018.

[27] McKee, M., Barnett, S., Block, R. \& Pearson, T. (2011). Impact of Communication on Preventive Services 
Among Deaf American Sign Language Users. American Journal of Preventive Medicine 41 (1) 75-79.

[28] SignHealth. (2013). Research into the health of deaf people. Available at: http://www.signhealth.org.uk/deafhealth-report-stage-one/. Accessed April 9, 2018.

[29] Shakespeare, T., Iezzoni, L.I. \& Groce, N.E. (2009). Disability and the training of health professionals. Lancet 374 (9704) 1815-1816.

[30] Zazove, P., Meador, H., Reed, B., Sen, A. \& Gorenflo, D. (2009). Cancer Prevention Knowledge of People with Profound Hearing Loss. Journal of General Internal Medicine 24 (3) 320-326.

[31] MacKinney, T., Walters, D., Bird, G. \& Nattinger, A. (1995). Improvements in preventive care and communication for deaf patients. Journal of General Internal Medicine 10 (3) 133-137.

[32] Bat-Chava, Y., Martin, D. \& Kosciw, J. (2005). Barriers to HIV/AIDS knowledge and prevention among deaf and hard of hearing people. AIDS Care 17 (5) 623634.

[33] Phillips, B. (1996). Bringing culture to the forefront: Formulating diagnostic impressions of deaf and hard-ofhearing people at times of medical crisis. Professional Psychology: Research and Practice 27 (2) 137-144.

[34] Harmer, L. (1999). Health care delivery and deaf people: practice, problems, and recommendations for change. Journal of Deaf Studies and Deaf Education 4 (2) 73-110.

[35] Genther, D., Frick, K., Chen, D., Betz, J. \& Lin, F. (2013). Association of Hearing Loss With Hospitalization and Burden of Disease in Older Adults. Journal of the American Medical Association 309 (22) 2322.

[36] Orima. (2004). Supply and demand for Auslan interpreters across Australia. Canberra, ACT: Australian Government Department of Family and Community Services.

[37] Zazove, P. (1993). The health status and health care utilization of deaf and hard-of-hearing persons. Archives of Family Medicine 2 (7) 745-752.

[38] Bachman, S., Vedrani, M., Drainoni, M., Tobias, C. \& Maisels, L. (2006). Provider Perceptions of Their Capacity to Offer Accessible Health Care for People With Disabilities. Journal of Disability Policy Studies 17 (3) 130-136.

[39] Barnett, S. \& Franks, P. (2002). Health Care Utilization and Adults Who Are Deaf: Relationship with Age at Onset of Deafness. Health Services Research 37 (1) 103-118.

[40] Tamaskar, P. (2000). Preventive Attitudes and Beliefs of Deaf and Hard-of-Hearing Individuals. Archives of Family Medicine 9 (6) 518-525.

[41] SignHealth. (2014). A Report Into The Health Of

Deaf People (detailed version of Sick Of It, for professionals). Available at:

http://www.signhealth.org.uk/sick-of-it-reportprofessionals/. Accessed April 9, 2018. 